\title{
Fully printed wireless LC sensor for heavy metal detection
}

\author{
Avuthu S. G. Reddy ${ }^{1}$, Ali Eshkeiti ${ }^{1}$, Binu B. Narakathu', Marian Rebros², Erika Rebrosova², \\ Margaret Joyce ${ }^{2}$, Massood Z. Atashbar, \\ ${ }^{1}$ Department of Electrical and Computer Engineering, Western Michigan University, Kalamazoo, MI, \\ USA, \\ saiguruva.r.avuthu@wmich.edu \\ ${ }^{2}$ Center for Advancement of Printed Electronics, Western Michigan University, Kalamazoo, MI, USA
}

\begin{abstract}
:
This paper reports on the successful development of a fully printed wireless LC sensor for the detection of toxic heavy metals. The sensor, consisting of an inductor, detection coil and interdigitated electrodes (IDE) in planar form, was fabricated using screen and gravure printing technologies on a flexible polyethylene-terephthalate (PET) substrate with silver based ink as metallization. The capability of the printed LC sensor for detecting very low concentrations of toxic heavy metals was demonstrated. The wireless response of the printed LC sensor revealed a very high sensitivity at picomolar levels of cadmium sulphide (CdS) and lead sulphide (PbS).
\end{abstract}

Key words: Printed electronics, LC sensor, wireless, gravure printing, screen printing, heavy metals.

\begin{abstract}
Introduction
Over the past decade, a lot of interest has been centered on the development of efficient, low cost and portable sensing systems for the detection of heavy metals in the food processing and environmental industries [1-4]. Toxic heavy metals, which are major environmental pollutants in land and water, are non-biodegradable and therefore remain in the ecosystem and food chain [5]. They have a high potential of causing various disease in humans and animals like renal failure, chronic toxicity, liver damage and ultimately loss of life [6]. Studies have reported on the use of various techniques for the detection of toxic heavy metals. To name a few, titration method [7], colorimetric analysis [8] and electrochemical impedance spectroscopy [9]. Although these techniques are sensitive enough, they require complicated instrumentation along with high manufacturing and operational costs.
\end{abstract}

In recent years, research has been focusing towards the development of low cost wireless sensors for applications in the environmental, food and biomedical industries [10-11]. Wireless sensing is usually performed in active and passive sensing methods. Active sensing method uses amplifiers, radio frequency (RF) circuits, batteries and antennas which make the sensors complex and expensive [12]. On the other hand, passive sensing method uses a basic inductive capacitor (LC) circuit that does not require complex circuits, are battery free and most importantly cost effective when compared to the active wireless sensors [13]. LC sensors are usually fabricated using conventional CMOS based techniques, which are typically expensive. The recent trend of using traditional printing methods in the field of printed electronics (PE) is a promising technique for the fabrication of low cost sensors.

$\mathrm{PE}$ is emerging as an alternate solution to traditional CMOS based techniques for fabrication of electronic devices which requires complex fabrication steps, needs high operating temperatures and ultimately is a costly process [14]. PE uses additive printing methods that can work on flexible substrates, uses less complex fabrication steps and reduces wastage of resources which leads to a cost effective fabrication method. Among all the printing methods, gravure, screen, inkjet and flexographic printing techniques have received significant attention for the fabrication of electronic devices such as displays [15], thin film transistors (TFT's) [16] and solar cells [17]. Although, recent studies have been reported on the fabrication of sensors using conventional printing techniques, there are no reports on the printing of wireless flexible LC sensors for toxic heavy metals detection.

In this work, the gravure and screen printing techniques was used to fabricate a fully printed LC sensor on a flexible substrate using silver based inks as metallization. Quantitative 
detection of toxic heavy metals like cadmium sulfide (CdS) and lead sulfide ( $\mathrm{PbS}$ ), was used to demonstrate the feasibility of the printed LC sensor.

\section{Screen printing}

Screen printing is a push through process in which the substrate is not in direct contact with the mask or image carrier (as shown in Fig. 1). The main components of the screen printing are a squeegee and a screen printing plate. The ink is applied on top of the screen over which the rubber squeegee is swept over with high pressure. This causes the ink to pass through the screen and is transferred onto the substrate [18].

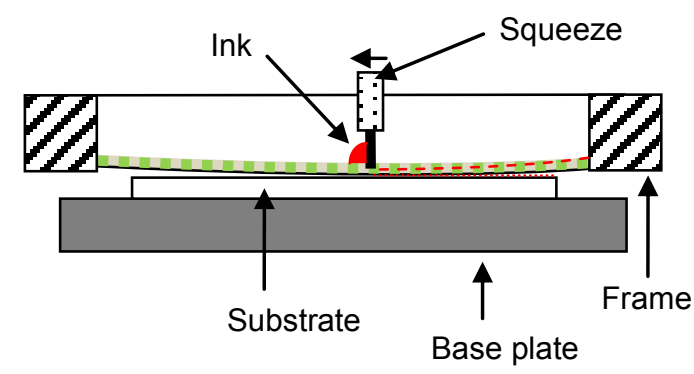

Fig. 1. Screen printing.

\section{Gravure printing}

Gravure printing is known for its high quality printing, fast output, robustness of the process and use of low viscosity inks. Image carrier (gravure cylinder), ink fountain, doctor blade and impression cylinder are the basic components of a typical gravure system (as shown in Fig. 2). The gravure cylinder has small cells or image areas on the surface that are responsible for carrying ink from the ink fountain to the substrate. Transferring the ink from the cells onto the substrate is assisted by the impression cylinder [19].

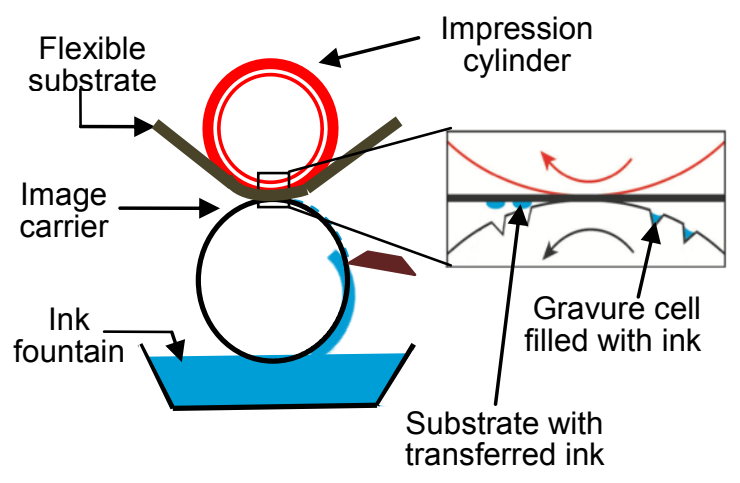

Fig. 2. Gravure printing.

\section{Sensor fabrication}

The passive LC sensor was fabricated using the gravure and screen printing techniques. Melinex ST 506, flexible polyethyleneterephthalate (PET) from DuPont Teijin Films was used as a substrate. TEC-PR-020, a silver nanoparticle based ink, and Electrodag 479SS, a silver ink, from Henkel was used for metallization in gravure and screen printing, respectively.

The wireless LC sensor consists of printed interdigitated electrodes (IDE's) and an inductor in planar form. Fig. 3(a) shows the screen printed flexible planar inductor with electrode dimensions of $200 \mu \mathrm{m}$ line width and 12 turns. The gravure printed IDE's, consisting of 8 pair of electrodes with $8600 \mu \mathrm{m}$ length, $200 \mu \mathrm{m}$ width and spacing, is shown in Fig. 3(b). The printed inductor was attached to the printed IDE's using connecting wires and $\mathrm{Ag}$ conductive epoxy (MG chemicals ${ }^{\circledR}$ ) to form a resonant LC circuit.

\section{Experimental}

CdS and $\mathrm{PbS}$ (in crystalline form) were purchased from Sigma-Aldrich Chemical Company. CdS and $\mathrm{PbS}$ were dissolved in deionized water (DI) to obtain concentrations of $1 \mathrm{pM}, 100 \mathrm{pM}, 1 \mathrm{nM}, 100 \mathrm{nM}$ and $100 \mu \mathrm{M}$. Fig. 4 shows the block diagram of the experiment setup. An Agilent impedance analyzer (4395A) was used to remotely monitor the LC sensors by measuring the impedance of the detection coil (screen printed planar inductor). Calibration for wires and probes was done before taking measurements. The data was recorded and analyzed using a custom built LabVIEW program on PC connected to the impedance analyzer via GPIB cable. $100 \mu \mathrm{l}$ of varying concentrations of $\mathrm{CdS}$ and $\mathrm{PbS}$ were loaded onto the LC sensor using a pipette. The frequency spectrum, from $32 \mathrm{MHz}$ to $33 \mathrm{MHz}$,

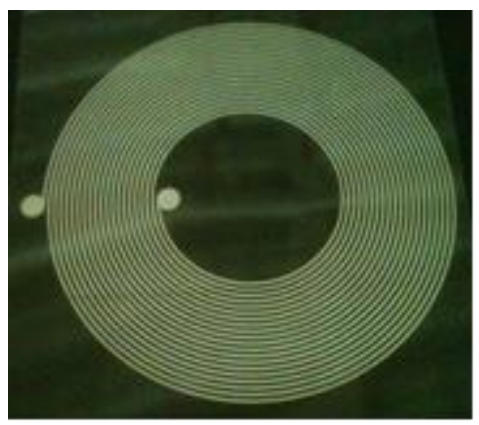

(a)

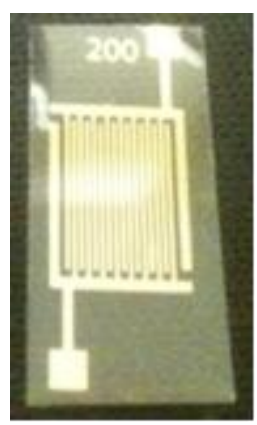

(b)
Fig. 3. (a) Screen printed planar inductor and (b) Gravure printed IDE's. 


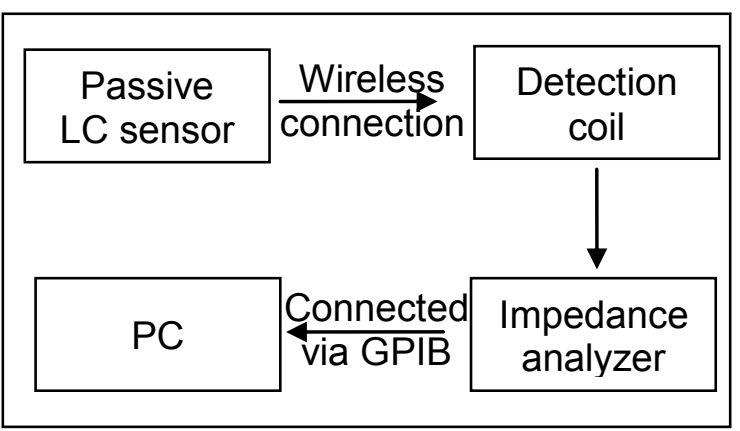

Fig. 4. Experiment setup.

of the printed LC sensor was wirelessly monitored by the detection coil. All the measurements were conducted at room temperature.

\section{Results and Discussion}

The response of the printed LC sensor was first tested towards CdS. A reference signal was established by placing $100 \mu \mathrm{l} \mathrm{DI}$ on the IDE's. The phase shift of the LC sensor was monitored for various concentrations of the CdS. The change in frequency of the LC sensor with respect to concentration of CdS is shown in Fig. 5. The resonant frequency change $(\Delta f)$ of the LC sensor was $1.2 \mathrm{kHz}, 2.5 \mathrm{kHz}, 16.2 \mathrm{kHz}$ and $40 \mathrm{kHz}$ when compared to base $\mathrm{DI}$, for $1 \mathrm{pM}, 100 \mathrm{pM}, 1 \mathrm{nM}$, and $100 \mathrm{nM}$ concentrations of CdS, respectively. It is worth noting that the detection of CdS was made possible at concentrations as low as $1 \mathrm{pM}$ while the US Food and Drug Administration (USFDA) toxicity limit of cadmium is $3 \mu \mathrm{M}$ [20].

Similarly, the response of the printed LC sensor was tested towards varying concentrations of $\mathrm{PbS}$. Fig. 6 depicts the percentage change in resonant frequency of the LC sensor with respect to the change in concentration of $\mathrm{PbS}$. It was observed that the percentage change in frequency was $0.1 \%, 0.3 \%, 0.35 \%$ and $0.4 \%$ for $1 \mathrm{pM}, 100 \mathrm{pM}, 100 \mathrm{nM}$ and $100 \mu \mathrm{M}$ concentrations of $\mathrm{PbS}$, respectively when

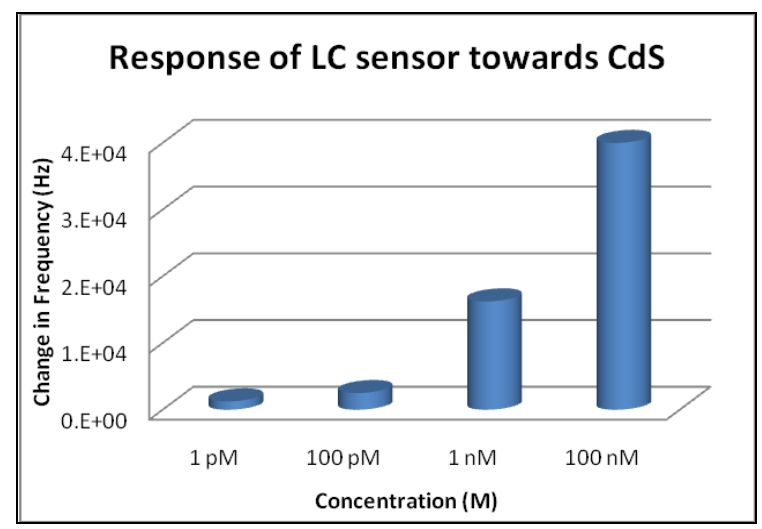

Fig. 5. Wireless resonant frequency response of the $L C$ sensor towards varying concentrations of CdS.

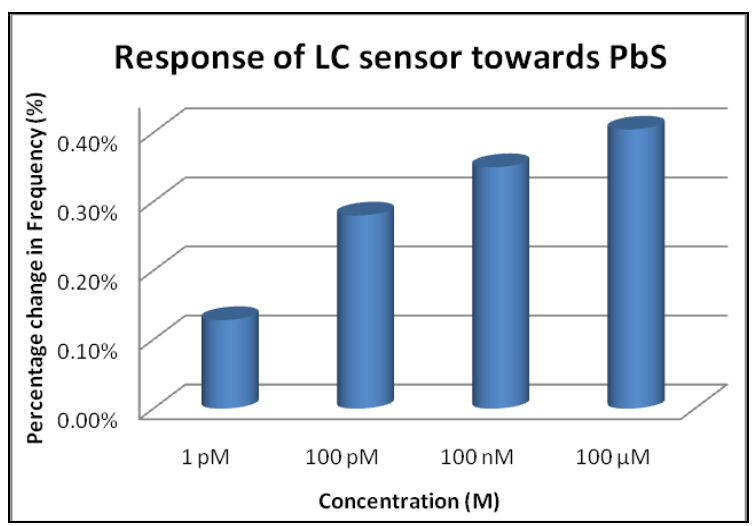

Fig. 6 Percentage change in resonant frequency of the $L C$ sensor towards varying concentrations of $\mathrm{PbS}$.

compared to base $\mathrm{DI}$. PbS was detected at concentrations as low as $1 \mathrm{pM}$. This is well below the limit of $3 \mu \mathrm{M}$ regulated by the USFDA [20].

\section{Conclusion}

A fully printed LC sensor was successfully fabricated using gravure and screen printing techniques on flexible PET substrate with electrode dimensions of $200 \mu \mathrm{m}$ width and spacing. Ag based ink was used for metallization. The feasibility of the device to distinguish among various concentrations of heavy metals such as $\mathrm{CdS}$ and $\mathrm{PbS}$ was demonstrated. The measured change in resonant frequency of the LC sensor towards $1 \mathrm{pM}$ concentration of $\mathrm{CdS}$ and $\mathrm{PbS}$ showed a variation of $1.2 \mathrm{kHz}$ and $40 \mathrm{kHz}$, respectively from the base DI. The results obtained show a promising potential of fully printed flexible wireless sensors for the detection of toxic heavy metals. Further research is underway to improve the sensitivity and selectivity of the sensor towards various heavy metal compounds.

\section{Acknowledgement}

This work has been partially supported by the U.S. Army Grant 204 no.WS911QY-07-1-0003 and W911NF-09-C-0135.

\section{References}

[1] J. Morton, N. Havens, A. Mugweru, A. K. Wanekaya, Detection of trace heavy metal ions using carbon nanotube- modified electrodes, Electroanalysis 21, 1597-1603 (2009); doi: 10.1002/elan.200904588.

[2] I. Gammoudi, H. Tarbague, A. Othmane, D. Moynet, D. Rebière, R. Kalfat, C. Dejous, Love-wave bacteria-based sensor for the detection of heavy metal toxicity in liquid medium, Biosensors and Bioelectronics 26, 1723-1726 (2010); 10.1016/j.bios.2010.07.118. 
[3] Q. H. Zheng, C. H. Jang, Liquid crystalbased sensors for the detection of heavy metals using surface-immobilized urease, Colloids and Surfaces B: Biointerfaces 88 , 622- $626 \quad$ (2011); doi: 10.1016/j.colsurfb.2011.07.052.

[4] M. Souiri, I. Gammoudi, H. B. Ouada, L. Mora, T. Jouenne, N. J. Renault, C. Dejous, A. Othmane, A.C. Duncan, Escherichia coli-functionalized magnetic nanobeads as an ultrasensitive biosensor for heavy metals, Procedia Chemistry 1, 1027-1030 (2009); doi: 10.1016/j.proche.2009.07.256.

[5] G. Aragay, J. Pons, A. Merkoci, Recent trends in macro-, micro-, and nanomaterialbased tools and strategies for heavy-metal detection, Chemical Reviews 111, 34333458 (2011); doi: 10.1021/cr100383r.

[6] O. Chailapakul, S. Korsrisakul, W. Siangproh, K. Grudpan, Fast and simultaneous detection of heavy metals using a simple and reliable microchipelectrochemistry route: An alternative approach to food analysis, Talanta 74,683 689 (2008); doi: 10.1016/j.talanta.2007.06 034

[7] K. V. Raju, G.D. Sudhakar, T. B. Patrudu, Spectrophotometric titration of resorufin and resazurin with iron(II) in strong phosphoric acid medium and resorufin as a new redox indicator in the reductimetric titration of some metal ions, Asian Journal of Chemistry 19, 683-692 (2007).

[8] A. Abbaspour, M. A. Mehrgardi, A. Noori, M. A. Kamyabi, A. K. Nezhad, M. N. Soltani Rad, Speciation of iron(II), iron(III) and fullrange $\mathrm{pH}$ monitoring using paptode: $\mathrm{A}$ simple colorimetric method as an appropriate alternative for optodes Sensors and Actuators B: Chemicals 113, 857-865 (2006); doi: 10.1016/j.snb.2005.03.119.

[9] B. B. Narakathu, M. Z. Atashbar, B. E. Bejcek, Improved detection limits of toxic biochemical species based on impedance measurements in electrochemical biosensors, Biosensors and Bioelectronics 26, 923-928 (2010); doi: 10.1016/j.bios.2010.06.051.

[10] K. G. Ong, C. A. Grimes, A resonant printed-circuit sensor for remote query monitoring of environmental parameters, Smart Materials and Structures 9, 421-428 (2000); doi: 10.1088/0964-1726/9/4/305.

[11] M. Yvanoff, J. Venkataraman, L. Fuller, Impact of multiple tissue layers on an implantable LC sensor, Microwave and Optical Technology Letters, 50, 783-787 (2008); doi: 10.1002/mop.23216.

[12] W. Mokwa, Medical implants based on microsystems, Measurement Science and
Technology 18, 47-57 (2007); doi: 10.1088/0957-0233/18/5/R01.

[13] S. T. J. Kaiser, Passive telemetric readout system, IEEE Sensors Journal 6, 13401345 (2006); doi: 10.1109/JSEN.2006.881395.

[14] C. Reese, M. Roberts, M. M Ling, Z. Bao, Organic thin film transistors, Materials Today 7, 20-207 (2004); doi: 10.1016/S1369-7021(04)00398-0.

[15] R. Sakurai, R. Hattori M. Asakawa, T. Nakashima, I. Tanuma, A. Yokoo, N. Nihei, Y. Masuda, A flexible electronicpaper display with an ultra-thin and flexible LSI driver using quick-response liquidpowder technology, Journal of the Society for Information Display 16, 155-160 (2008); doi: $10.1889 / 1.2835022$.

[16] C. T. Liu, W. H. Lee, J. F. Su, Pentacenebased thin film transistor with Inkjet-printed nanocomposite high-K dielectrics, Active and Passive Electronic Components 2012, 1-7 (2012); doi: 10.1155/2012/921738.

[17] J. D. Lee, H. Y. Kwon, M. J. Kim, E. J. Lee, H. S. Lee, S. H. Lee, The investigation of one step annealing for plated $\mathrm{Ni} / \mathrm{Cu}$ contact solar cells, Renewable Energy 42, 1-3 (2012); doi:10.1016/j.renene.2011.10.007.

[18] N. Lim, J. Kim, S. Lee, N. Kim and G. Cho, Screen printed resonant tags for electronic article surveillance tags, IEEE Transactions on Advanced Packaging, 32, 72-76 (2009); doi: 10.1109/TADVP.2008.2006656.

[19] A. S. G. Reddy, B. B. Narakathu, M. Z. Atashbar, M. Rebros, E. Hrehorova and M. Joyce, Printed electrochemical based biosensors on flexible substrates, Proceedings of IEEE Sensors, 1596-1600 (2010); doi: 10.1109/ ICSENS.2010. 5690281.

[20] R. W. Sheets, Extraction of lead, cadmium and zinc from overglaze decorations on ceramic dinnerware by acidic and basic food substances, Science Total Environmental 197, 167-175 (1997); doi: 10.1016/S0048-9697(97)05431-4. 